\title{
Penilaian Usability Sistem Gasurkes "Go Bumil" untuk Pencarian Ibu Hamil di Wilayah Kota Semarang
}

\author{
Undari Nurkalis*, Kusworo Adi**, Farid Agushybana*** \\ *Alumni Magister Ilmu Kesehatan Masyarakat Universitas Diponegoro, \\ **Fakultas Sains dan Matematika, Universitas Diponegoro, Semarang \\ ***Fakultas Kesehatan Masyarakat, Universitas Diponegoro, Semarang \\ Email: undari.nurkalis@gmail.com
}

\section{ABSTRACT:}

The Gasurkes System "Go Bumil" is an application system developed to improve the search performance of pregnant women by village level maternal and child health surveillance officers in the Semarang City area. Usability evaluation on the "Go Bumil" application system needs to be done to find out the usefulness of the application system for users.

This type of research uses a preexperimental design in a single group. Data collection used the PSSUQ questionnaire (Post Study System Usability Questionnaire). The research subjects were 12 respondents from urban KIA gasurkes, 104 respondents to pregnant women and postpartum mothers. The object of research is the "Go Pregnancy" application. Data processing methods use descriptive analysis using a weighted average.

The results of the usability evaluation of the "Go Bumil" application with respondents to KIA gaskes, pregnant and postpartum mothers as a whole were satisfied with the application system developed. The overall results of the overall assessment on kelurahan gas, pregnant women and postpartum mothers in the category of system usefulness $=6.02$ (range values 6.00 6.99 state respondents agree), information quality $=5.99$ (range of values 5,00 5.99 states the respondent somewhat agrees), interface quality $=5.99$ (range values

5,00 - 5,99 state respondents somewhat agree) and overall satisfaction $=6.01$ (range values 6,00 - 6,99 state respondent agreed). Based on the evaluation of the system usefulness, information quality, interface quality and overall satisfaction categories, it can be concluded that the respondents were satisfied with the "Go Bumil" application.

Keywords: Information System; Gasurkes KIA; PSSUQ

\section{PENDAHULUAN}

Sistem Gasurkes "Go Bumil" adalah sistem aplikasi yang dikembangkan untuk meningkatkan kinerja pencarian ibu hamil oleh petugas surveilans kesehatan ibu dan anak (gasurkes KIA) tingkat kelurahan di wilayah Kota Semarang. Sistem aplikasi "Go Bumil" mencakup sistem aplikasi berbasis website dengan wewenang akses sebagai administrator (gasurkes KIA Kota) dan sistem aplikasi berbasis android dengan wewenang akses sebagai user (gasurkes KIA kelurahan, ibu hamil dan ibu nifas).

Penggunaan teknologi smartphone saat ini mulai berkembang pesat. Smartphone memiliki teknologi tinggi yang terkadang 
memiliki fungsi menyerupai komputer. Smartphone merupakan komputer mini yang mempunyai kapabilitas sebuah telepon. Banyak platform dari smartphone yang berkembang saat ini, dilihat dari sistem operasi dan hardware yang digunakan. Android merupakan platform yang Open Source. Android didukung Google Maps sehingga dapat digunakan untuk menampilkan dan mengatur peta lokasi secara mudah. Peta mobile memberikan bantuan pengguna dalam mengetahui dimana lokasi mereka dan kemana mereka akan pergi sementara mereka telah bergerak. Kegunaan peta mobile berdampak dalam mengurangi ketidaknyamanan dan meningkatkan waktu yang dimiliki pengguna sementara mereka mencari lokasi tujuan. ${ }^{1,2}$ Penerapan teknologi informasi dapat menjadi sangat penting dan sangat membantu dalam meningkatkan kualitas pelayanan dari segi efektif dan efisiensi.

Uji usability merupakan alat yang umum digunakan untuk mengevaluasi kegunaan aplikasi mobile dalam proses pengembangan. Penilaian usability sangat penting dalam pengembangan produk dan layanan dasar dalam teknologi informasi. Usability adalah kunci untuk membuat sistem menjadi mudah dipelajari, digunakan dan melihat keberhasilan pengembangan aplikasi. ${ }^{3}$ Usability meliputi konsistensi dan kemudahan yang mana user dapat memanipulasi dan menavigasi situs web, kejelasan interaksi, kemudahan membaca, penataan informasi, kecepatan dan tata letak. Usability meningkatkan desain user interface dengan mengevaluasi organisasi, presentasi dan interaktiitas interface. ${ }^{4}$

$$
\text { Post-Study System Usability }
$$

Questionairre (PSSUQ) adalah salah satu paket kuesioner yang dapat digunakan untuk mengukur usability. PSSUQ merupakan instrumen penelitian yang dikembangkan untuk melakukan evaluasi usability di IBM. PSSUQ digunakan untuk menilai kepuasan pengguna berdasarkan aspek usability dengan mengelompokkan menjadi empat kategori yaitu, system usefullnes, information quality, interface quality, overall satisfaction. Sistem aplikasi "Go Bumil" merupakan aplikasi yang baru. Sistem aplikasi ini perlu dilakukan uji usability untuk mengetahui kegunaan sistem aplikasi bagi pengguna.

\section{METODE PENELITIAN}

Jenis penelitian menggunakan rancangan pre-eksperimental pada kelompok tunggal. Penelitian dilakukan pada bulan Juni - November 2018. Pengumpulan data menggunakan kuesioner PSSUQ (Post Study System Usability Questionnaire). Subjek penelitian adalah 12 responden gasurkes KIA kelurahan, 104 responden ibu hamil dan ibu nifas. Obyek penelitian adalah aplikasi "Go Bumil". Metode pengolahan data menggunakan analisis deskriptif dengan menggunakan rata-rata tertimbang. Hasil dan interpretasi PSSUQ dilakukan melalui parameter yang ditetapkan dari skala aslinya. Lewis mengembangkan aturan untuk menghitung skor PSSUQ dan mendefinisikan skor total global dan skor parsial untuk subskala yang terkait dengan PSSUQ ${ }^{5}$ : i) overall: rata-rata tanggapan dari butir 1 hingga 19 yang meliputi 1) Secara keseluruhan, saya puas dengan kemudahan penggunaan sistem aplikasi ini, 2) Sistem aplikasi ini mudah untuk digunakan, 3) Saya secara efektif dapat menyelesaikan tugastugas dan skenario menggunakan sistem aplikasi ini, 4) Saya bisa menyelesaikan tugas dan skenario dengan cepat menggunakan sistem aplikasi ini, 5) Saya dengan efisien dapat menyelesaikan tugas dan skenario menggunakan sistem aplikasi ini, 6) Saya merasa nyaman menggunakan sistem aplikasi ini, 7) Mudah untuk mempelajari sistem aplikasi ini, 8) Saya yakin, dengan sistem aplikasi ini dapat meningkatkan produktifitas pekerjaan saya, 9) Sistem aplikasi ini memberikan pesan kesalahan yang jelas memberitahu saya bagaimana untuk memperbaiki masalah, 10) Setiap kali saya melakukan kesalahan dengan menggunakan sistem aplikasi, saya bisa pulih dengan mudah dan cepat, 11) Informasi (seperti online pesan bantuan, pada layar, dan dokumentasi lainnya) disediakan dengan jelas oleh sistem aplikasi ini, 12) Mudah untuk menemukan informasi yang saya butuhkan, 13) Informasi yang disediakan pada sistem aplikasi ini mudah dimengerti, 14) Informasi yang dihasilkan sistem aplikasi 
ini efektif dan dapat membantu menyelesaikan tugas dan perencanaan pekerjaan, 15) Kebutuhan Informasi organisasi dilayar sistem aplikasi dapat terlihat secara jelas untuk kebutuhan, 16) Tampilan muka sistem aplikasi ini menyenangkan, 17) Saya suka menggunakan tampilan muka sistem aplikasi ini, 18) Sistem aplikasi ini memiliki semua fungsi dan kemampuan yang saya harapkan, 19) Secara keseluruhan, saya puas dengan sistem aplikasi ini; ii) system usefulness (SysUse): rata-rata respons dari butir 1 hingga 8 yang meliputi 1) Secara keseluruhan, saya puas dengan kemudahan penggunaan sistem aplikasi ini, 2) Sistem aplikasi ini mudah untuk digunakan, 3) Saya secara efektif dapat menyelesaikan tugas-tugas dan skenario menggunakan sistem aplikasi ini, 4) Saya bisa menyelesaikan tugas dan skenario dengan cepat menggunakan sistem aplikasi ini, 5) Saya dengan efisien dapat menyelesaikan tugas dan skenario menggunakan sistem aplikasi ini, 6) Saya merasa nyaman menggunakan sistem aplikasi ini, 7) Mudah untuk mempelajari sistem aplikasi ini, 8) Saya yakin, dengan sistem aplikasi ini dapat meningkatkan produktifitas pekerjaan saya; iii) information quality (InfoQual): rata-rata tanggapan dari butir 9 hingga 15 yang meliputi 9) Sistem aplikasi ini memberikan pesan kesalahan yang jelas memberitahu saya bagaimana untuk memperbaiki masalah, 10) Setiap kali saya melakukan kesalahan dengan menggunakan sistem aplikasi, saya bisa pulih dengan mudah dan cepat, 11) Informasi (seperti online pesan bantuan, pada layar, dan dokumentasi lainnya) disediakan dengan jelas oleh sistem aplikasi ini, 12) Mudah untuk menemukan informasi yang saya butuhkan, 13) Informasi yang disediakan pada sistem aplikasi ini mudah dimengerti, 14) Informasi yang dihasilkan sistem aplikasi ini efektif dan dapat membantu menyelesaikan tugas dan perencanaan pekerjaan, 15) Kebutuhan Informasi

organisasi dilayar sistem aplikasi dapat terlihat secara jelas untuk kebutuhan; dan iv) interface quality (IntQual): rata-rata tanggapan dari butir 16-18 yang meliputi 16) Tampilan muka sistem aplikasi ini

\begin{tabular}{|l|c|c|c|c|c|}
\hline \multirow{2}{*}{ Uji Fungsional } & \multicolumn{5}{|c|}{ Nilai } \\
\cline { 2 - 6 } & Mean & Median & Min & Maks & Modus \\
\hline $\begin{array}{l}\text { System } \\
\text { usefulness }\end{array}$ & 6,01 & 6 & 4,38 & 7 & 6 \\
\hline $\begin{array}{l}\text { Information } \\
\text { Quality }\end{array}$ & 5,92 & 6 & 4,86 & 7 & 6 \\
\hline $\begin{array}{l}\text { Interface } \\
\text { Quality }\end{array}$ & 5,92 & 6 & 5 & 7 & 6 \\
\hline $\begin{array}{l}\text { Overall } \\
\text { Satisfaction }\end{array}$ & 5,97 & 6 & 5 & 7 & 6 \\
\hline
\end{tabular}

menyenangkan, 17) Saya suka menggunakan tampilan muka sistem aplikasi ini, 18) Sistem aplikasi ini memiliki semua fungsi dan kemampuan yang saya harapkan. Skor akhir dari PSSUQ dihitung berdasarkan rata-rata dari skor item dan skor dari subskala. Skor yang lebih tinggi dikaitkan dengan kegunaan yang lebih baik.

\section{Hasil dan Pembahasan}

Pada penelitian ini pengembangan aplikasi diukur dengan menggunakan menggunakan paket kuesioner PSSUQ (Post Study System Usability Questionnaire) yang dapat digunakan untuk mengukur usability.

Tabel 1. Hasil uji fungsional dengan Gasurkes KIA Kelurahan

Berdasarkan hasil distribusi frekuensi dengan paket kuesioner PSSUQ diatas, penilaian kategori information quality (InfoQual) dan interface quality (InterQual) memiliki nilai rata-rata terendah yaitu 5,92 dan kategori system usefulness (SysUse) memiliki nilai tertinggi yaitu 6,01 . Sedangkan kategori overall satisfaction (overall) memiliki nilai rata-rata yaitu 5,97.

Tabel 2. Hasil uji fungsional dengan Ibu hamil dan nifas

\begin{tabular}{|l|c|c|c|c|c|}
\hline \multirow{2}{*}{$\begin{array}{c}\text { Uji } \\
\text { Fungsional }\end{array}$} & \multicolumn{5}{|c|}{ Nilai } \\
\cline { 2 - 6 } & Mean & Median & Min & Maks & Modus \\
\hline $\begin{array}{l}\text { System } \\
\text { usefulness }\end{array}$ & 6,04 & 6,13 & 2,63 & 7 & 7 \\
\hline $\begin{array}{l}\text { Information } \\
\text { Quality }\end{array}$ & 6,06 & 6,29 & 3 & 7 & 7 \\
\hline $\begin{array}{l}\text { Interface } \\
\text { Quality }\end{array}$ & 6,06 & 6,21 & 2,84 & 7 & 7 \\
\hline $\begin{array}{l}\text { Overall } \\
\text { Satisfaction }\end{array}$ & 6,05 & 6,21 & 2,84 & 7 & 7 \\
\hline
\end{tabular}


Berdasarkan hasil distribusi frekuensi dengan paket kuesioner PSSUQ diatas, penilaian kategori system usefulnesss (SysUse) memiliki nilai rata-rata terendah yaitu 6,04 dan kategori dengan nilai rata-rata tertinggi yaitu information quality (InfoQual) dan kategori interface quality (InterQual) dengan nilai 6,11. Sedangkan kategori overall satisfaction (overall) memiliki nilai rata-rata yaitu 6,05 .

\section{System Usefulness}

System usefulness merupakan item yang terdapat dalam penilaian PSSUQ untuk menilai kegunaan sistem apakah sudah sesuai dengan kebutuhan pengguna atau belum. Secara keseluruhan rata-rata hasil penilaian system usefulness adalah 6,2. Nilai tersebut menunjukkan tingkat persetujuan pengguna terhadap kegunaan sistem ( range nilai 6,00 6,99 menyatakan responden setuju ). System usefulnesss terkait dengan seberapa relevan, informatif, bermakna, penting, bermanfaat, dan signifikan suatu informasi untuk pengambilan keputusan pengguna. Kualitas sistem berkorelasi positif dengan kegunaan dan berdampak kuat dalam persepsi kegunaan sistem. ${ }^{6,7}$ Ming-Chi Lee (2010) secara empiris melakukan validasi hipotesis bahwa konfirmasi harapan pengguna secara positif berkaitan dengan kegunaan yang dirasakan dari aplikasi. ${ }^{8}$ Ketika harapan telah terpenuhi maka hal tersebut akan mengarah pada kepuasan yang positif. Studi empiris oleh Sun, et al. (2008) dan Lee \& Lehto (2013) menunjukkan hubungan positif antara manfaat yang dirasakan dan kepuasan pengguna.., 10

\section{Information Quality}

Information quality merupakan item yang terdapat dalam penilaian PSSUQ untuk mengukur kualitas sistem yang dilihat dari segi kemudahan, keakuratan, kesesuaian dengan kebutuhan dan ketepatan waktu penyajian informasi. ${ }^{11}$ Secara keseluruhan rata-rata hasil penilaian information quality adalah 5,99. Nilai tersebut menunjukkan tingkat persetujuan pengguna terhadap informasi yang dihasilkan oleh sistem aplikasi ( range nilai 5,00 - 5,99 menyatakan responden agak setuju ). Kepuasan terhadap kualitas informasi meliputi pesan kesalahan untuk memperbaiki masalah, dapat segera pulih setelah melakukan kesalahan, kejelasan informasi yang ditampilkan aplikasi jelas, kemudahan menemukan informasi, kemudahan memahami informasi, efektivitas informasi yang dihasilkan untuk membantu menyelesaikan tugas dan kejelasan tampilan terhadap kebutuhan informasi. Information quality (IQ) merupakan salah satu prediktor yang kuat untuk menilai kemudahan penggunaan dan kepuasan pengguna. ${ }^{12,13}$ Information quality menurut Lee et al. (2002) dikelompokkan menjadi empat kriteria ${ }^{14}$ : a) IQ intrinsik, yang menyiratkan bahwa informasi memiliki kualitas dalam dirinya sendiri seperti akurasi, keandalan, kredibilitas, konsisten, dan objektivitas; b) IQ kontekstual, yang mengacu pada persyaratan utama bahwa informasi harus dihadapi dalam konteks tugas yang dihadapi seperti ketepatan waktu, relevansi, kelengkapan, dan mata uang; c) IQ representasional, yang mengacu pada cara penyajian informasi dalam konteks tertentu; dan (d) IQ aksesibilitas, yang menekankan pentingnya sistem komputer yang menyajikan informasi.

\section{Interface Quality}

Interface quality merupakan item yang terdapat dalam penilaian PSSUQ untuk memberikan penilaian terhadap kualitas antarmuka sistem yaitu berupa tampilan yang menarik dan kemudahan mengoperasikan. Secara keseluruhan rata-rata hasil penilaian interface quality adalah 5,99. Nilai tersebut menunjukkan tingkat persetujuan pengguna terhadap tampilan antarmuka yang disajikan oleh sistem aplikasi ( range nilai 5,00 - 5,99 menyatakan responden agak setuju ). Elemen kegunaan (misal kemudahan penggunaan navigasi dan kualitas interface) berdampak kuat pada kepuasan pengguna saat menggunakan. ${ }^{15}$ Konten dan desain antarmuka mempengaruhi persepsi, terutama pembelajar mobile karena sistem seluler memperkenalkan lebih banyak pembatasan pada desain. Desain Antarmuka Pengguna (UID) merupakan faktor penting dalam pengembangan aplikasi. UID yang baik mendorong kompatibilitas di berbagai perangkat. Kompatibilitas memiliki 
"pengaruh pada kemudahan penggunaan yang terkait dengan teknologi baru". ${ }^{16,17}$

Dalam merancang sistem aplikasi mobile perlu untuk mendesain tata letak tampilan antarmuka atau interface yang menarik serta sesuai dengan kebutuhan informasi. Tampilan layar yang terbatas menjadi salah satu kendalanya. Mahmoud mencatat bahwa teknologi seluler adalah "solusi paling kompleks" karena situs web harus dirancang untuk tata letak layar dan format file yang berbeda. ${ }^{18}$ Ukuran layar yang terbatas menyebabkan informasi yang ditampilan menjadi tantangan pada pengembangan aplikasi mobile. Kualitas interface yang baik meningkatkan kepuasan dan kemauan untuk menggunakan. Perangkat seluler dirancang untuk dapat digunakan dimana saja. Pengguna mungkin perlu melakukan beberapa aktivitas lain secara bersamaan saat menggunakan perangkat. ${ }^{19}$

\section{Overall Satisfaction}

Overall satisfaction merupakan penilaian dari keseluruhan kuesioner PSSUQ yang menunjukkan kepuasan pengguna Secara keseluruhan rata-rata hasil penilaian overall satisfaction adalah 6,01. Nilai tersebut menunjukkan tingkat persetujuan kepuasan secara keseluruhan pengguna terhadap sistem aplikasi ( range nilai 6,00 - 6,99 menyatakan responden setuju ). Kepuasan secara keseluruhan dilihat berdasarkan penilaian kegunaan sistem (system usefulness), kualitas informasi (information quality) dan kualitas tampilan antar muka (interface quality). Penelitian Zamzami (2013) mengukur kepuasan pengguna dengan melihat kualitas informasi, tampilan antar muka mobile dan kepuasan pengguna. Pengguna merasa puas dengan beberapa bagian seperti kejelasan aplikasi dan kemampuan untuk memahaminya. ${ }^{20}$

\section{KESIMPULAN}

Hasil evaluasi usability aplikasi "Go Bumil" dengan menggunakan kuesioner usability PSSUQ yaitu responden menyatakan bahwa mereka merasa puas. Hal ini dapat dilihat dari hasil rata - rata penilaian secara keseluruhan pada gasurkes kelurahan, ibu hamil dan ibu nifas pada kategori system usefulnesss $=6,02$ ( range nilai $6,00-6,99$ menyatakan responden setuju ), information quality $=5,99$ (range nilai 5,00 - 5,99 menyatakan responden agak setuju ), interface quality $=5,99$ (range nilai $5,00-5,99$ menyatakan responden agak setuju ) dan overall satisfaction $=6,01$ ( range nilai $6,00-6,99$ menyatakan responden setuju ).

\section{UCAPAN TERIMA KASIH}

Kami ingin mengucapkan terima kasih kepada Dinas Kesehatan Kota Semarang, Puskesmas Purwoyoso dan Puskesmas Ngaliyan atas dukungan dalam pelaksanaan evaluasi sistem aplikasi "Go Bumil". Kami juga berterima kasih kepada gasurkes KIA, ibu hamil dan ibu nifas yang ikut berpartisipasi untuk mendukung sistem aplikasi "Go Bumil".

\section{DAFTAR PUSTAKA}

1. Leitner G, Plattner S, and Hitz $M$. Usability Evaluation of mobile Applications in leisure oriented Contexts. 13th Int'l Conf on Info \& Comm; 2006; Switzerland: Technologies in Tourism.

2. Kjeldskov J, et al. Evaluating the Usability of a Mobile Guide: The influence of Location, Participants and Resources. Behavior and Information Technology (BIT). 2005; Vol.24.

3. Loureiro N, Fernandes M, Alvarelhão J, Ferreira, Alina C, Hilma M, Ana I et al. $A$ web-based platform for quality management of elderly care : usability evaluation of Ankira ${ }^{\circledR}$. Journal Procedia Computer Science. 2015; Vol. 64

4. Fuhling $\mathrm{A}$ and Lee $\mathrm{S}$. Assessing the Reliability, Validity and Adaptability of PSSUQ. 2005. Omaha : Americas Conference on Information Systems (AMCIS)

5. Lewis JR. Psychometric evaluation of the PSSUQ using data from five years of usability studies. Int. J. HumanComputer Interact. 2002; Vol.14(3-4)

6. Landrum, H. T., Prybutok, V. R., Strutton, D., \& Zhang, X. Examining the Merits of usefulness Versus use in an information service Quality and information system success Web-based 
Model. Information Resources Management Journal.2008;Vol. 21

7. Hwang, H., Chang, I., Chen, F., \& Wu, S. Investigation of the application of KMS for diseases classifications: A study in a Taiwanese hospital. Expert Systems with Applications.2008;Vol. 34

8. Lee M-C. Explaining and predicting users' continuance intention toward $e$ learning : An extension of the expectation-confirmation model. Computers \& Education. 2010;Vol. 54.

9. Pei-Chen Sun RJT, Glenn Finger, Yueh-Yang Chen, Dowming Yeh. What drives a successful e-Learning? An empirical investigation of the critical factors influencing learner satisfaction. Computers \& Education. 2008; Vol. 50.

10. Doo Young Lee MRL. User acceptance of YouTube for procedural learning: An extension of the Technology Acceptance Model. Computers \& Education. 2013; Vol. 61

11. Petter ,S., \& DeLone, W., \& McLean,E. Measuring Information Systems Success: Models, Dimensions, Measures, and Interrelationships. European Journal of Information Systems.2008;Vol.17

12. Kim, Hyejeong and Niehm, Linda S. The Impact of Website Quality on Information Quality, Value, and Loyalty Intentions in Apparel Retailing. Journal of Interactive Marketing.2009;Vol.23

13. Urbach ,N.,\& Smolnik ,S.,\& Riempp,G. An empirical investigation of employee portal success. The Journal of Strategic Information Systems.2010;Vol. 19

14. Yang W. Lee DMS, Beverly KK, and Richard YW. AIMQ: a methodology for information quality assessment. Information \& Management. 2002; Vol. 40.

15. Al- Manasraa,Excimirey Amer., Saleem Abu Zaidb, "Mohammed Khair"., TaherQutaishat, Fadi. Investigating the Impact of Website Quality on Consumers' Satisfaction in Jordanian Telecommunication Sector. Arab Economic And Business Journal. 2013; Vol.8

16. I-Fan Liu MCC, Yeali S.Sun, David Wiblec Chin-Hwa Kuo. Extending the TAM model to explore the factors that affect Intention to Use an Online Learning Community. Computers \& Education. 2010; Vol. 54.

17. Ronnie Cheung DV. Predicting user acceptance of collaborative technologies. An extension of the technology acceptance model for e-learning. Computers \& Education. 2010; Vol. 63.

18. Mahmoud SS. A Proposed Model for Distributing e-Courses Content through Mobile Technology Architectures. International Journal of Humanities and Social Sciences. 2008;Vol. 2.

19. Punchoojit L and Hongwarittorrn N. Usability Studies on Mobile User Interface Design Patterns : A Systematic Literature Review. Hindawi. 2017;Vol.22.

20. Zamzami I and Mahmud M. User Satisfaction On Smart Phone Interface Design; Information quality Evaluation. 2012 International Conference on Advanced Computer Science Applications and Technologies; 2013: IEEE 